\title{
O Teste Gap in Noise em crianças de 11 e 12 anos***
}

\author{
The Gap in Noise Test in 11 and 12-year-old children
}

\author{
Ana Paula Perez* \\ Liliane Desgualdo Pereira**
}

*Fonoaudióloga do Programa de Saúde Universidade Federal do Rio de Janeiro (UFRJ). Mestre em Distúrbios da Comunicação Humana pela Universidade Federal de São Paulo (Unifesp). Endereço para correspondência: Estrada Francisco da Cruz Nunes, 777 - Casa 111 - Niterôi RJ - CEP 24350-370 (popiperez@ig.com.br).

**Fonoaudióloga. Livre-Docente e Chefe do Departamento de Fonoaudiologia da Unifesp.

***Trabalho Realizado na Escola Municipal Henrique Dodsworth.

Artigo Original de Pesquisa

Artigo Submetido a Avaliação por Pares

Conflito de Interesse: não

Recebido em 07.07.2009

Revisado em 31.12.2009; 12.01.2010.

Aceito para Publicação em 01.02.2010.

\begin{abstract}
Background: gap detection in 11 and 12-year-old children. Aim: to investigate temporal resolution through the Gap in Noise test in children of 11 and 12 years in order to establish criteria of normal development. Method: participants were 92 children, with ages of 11 and 12 years, enrolled in elementary school, with no evidences of otologic, and/or neurologic, and/or cognitive disorders, as well as with no history of learning difficulties or school failure. Participants Besides that, their hearing thresholds were within normal limits and their verbal recognition in the dichotic test of digits was equal or superior to $95 \%$ of hits. All were submitted to the Gap in Noise test. The statistical analysis was performed by nonparametric tests with significance level of 0.05 (5\%). Results: the average of the gap thresholds was $5.05 \mathrm{~ms}$, and the average percentage of correct answers was $71.70 \%$. There was no significant statistical difference between the responses by age (eleven and twelve years), by ear (right and left), by gender (male and female). However, when comparing the tests, it was observed that the 1st test showed a higher percentage of identifications of gap, statistically significant than the 2nd test. Conclusion: in $78.27 \%$ of the population of this study, the gap thresholds were up to $5 \mathrm{~ms}$, response recommended as normality reference for the age group searched.
\end{abstract}

Key Words: Acoustic Stimulation; Auditory Perception; Hearing Tests; Child; Speech Perception; Humans.

\section{Resumo}

Tema: a detecção de gap em crianças de 11 e 12 anos. Objetivo: verificar o comportamento da resolução temporal, através do teste gap in noise, em crianças de onze e doze anos, a fim de subsidiar o estabelecimento de critérios de referência de normalidade. Método: participaram 92 crianças, com idades de 11 e 12 anos, matriculadas no ensino fundamental, sem evidências de doenças otológicas e/ou neurológicas e/ou cognitivas, assim como dificuldades de aprendizagem e histórico de repetência escolar. Ainda, apresentavam limiares audiométricos dentro da normalidade e reconhecimento verbal no teste dicótico de dígitos igual ou superior a $95 \%$ de acertos. Todos foram submetidos ao teste gap in noise. A análise estatística foi realizada por meio de testes não paramétricos com nível de significância de 0,05 . Resultados: a média dos limiares de gap foi de 5,05ms e a média da porcentagem de acertos foi de 71,70\%. Não houve diferença estatisticamente significante entre as respostas por faixa etária (onze e doze anos), por orelha (direita e esquerda) e por gênero (masculino e feminino). No entanto, ao se comparar as faixas-testes, observa-se que a primeira faixa-teste apresentou porcentagem maior de identificações de gap, estatisticamente significante em relação à segunda faixa-teste. Conclusão: em 78,27\% da população deste estudo, os limiares de gap obtidos foram de até $5 \mathrm{~ms}$, resposta recomendada como referência de normalidade para a faixa etária pesquisada.

Palavras-Chave: Estimulação acústica; Percepção Auditiva; Testes Auditivos; Criança; Humanos.

Referenciar este material como:

1 Perez AP, Pereira LD. The Gap in Noise Test in 11 and 12-year-old children (orignal title: O teste gap in noise em crianças de 11 e 12 anos). Pró-Fono Revista de 3 Atualização Científica. 2010 jan-mar;22(1):7-12. 


\section{Introduction}

The ability to discriminate temporal order alterations in a sound wave is named auditory temporal processing. Studies have reported that temporal processing may be a component that underlies many auditory processing abilities, including processing of verbal and non-verbal acoustic signals of language 1-2.

Temporal resolution, or temporal discrimination, is one of the auditory abilities of temporal processing. It refers to rapid changes on time-related acoustic aspects, allowing the detection of a brief interruption between two sounds 3 . The perception of such alterations requires an auditory system capable of detecting rapid changes in sound intensity and spectral fluctuations 4-5.

Several studies have reported that children with deficits in this ability are more likely to present language disorders and learning disabilities. In other words, the temporal resolution is extremely necessary for the comprehension of regular speech and the development of language 6-7.

The gap in noise test (GIN) was developed to study the temporal resolution in which the detection threshold of gap is determined - that is, the shortest time, in milliseconds, identified as an interruption on the sonorous stimulus 8 .

A study by Musiek et al. 1 presented preliminary results that demonstrated the sensitivity of the GIN test as being $73 \%$ and the specificity as $84 \%$ in identifying patients with central auditory system lesions. Such results prove that the GIN is a sensitive test for determining auditory processing disorders.

In order for the GIN test to be incorporated into the auditory processing assessment battery of tests, normality criteria for normal hearing individuals are necessary.

Therefore, the purpose of the present study was to assess the behavior of temporal resolution through the GIN test in normal hearing children with 11 and 12 years of age in order to subsidize the establishment of reference values.

\section{Method}

This study was approved by the Ethics Committee of the Federal University of São Paulo - Escola Paulista Paulista de Medicina under process number 0789/08. Parents or guardians of all subjects signed a consent form agreeing to the participation in this study and to the dissemination of results according to Resolution 196/96.

The study included 92 children: 46 girls and 46 boys. Forty-eight children were 11 years old and 44 were 12 years old. The procedures were performed at the school where sample was originated from, after review and approval of the research project by the Coordination of the establishment. A soundproof booth was installed on the establishment for the purpose of the study.

The adopted inclusion criteria were: presence of audiometric thresholds within normal limits; verbal recognition on the test dichotic digits with correct identifications higher than or equal to 95\% for both ears; current enrolment in school; and presence of age of 11 or 12 years. Through the process of interviewing, children who had evidence of ear, and/or neurological, and/or cognitive diseases and learning difficulties were excluded from the sample. Children with a history of school failure were also excluded from the study given the possibility of presenting learning disability.

The GIN test, proposed by Musiek et al. 1, was applied through a CD recording material that was presented via headphones using an Interacoustics CE 10 audiometer attached to a Couby CD player. The test was carried out in a soundproof booth. The stimulus was applied monaurally to $50 \mathrm{dBHL}$, based on the average of the thresholds of 500, 1000 and $2000 \mathrm{~Hz}$.

In the GIN test, the stimuli are divided into four tracks of test and one track of practice. Six-second segments of white noise are interspersed with random gaps (intervals of silence). Gaps are randomized and present varying lengths (2, 3, 4, 5, 6, 8, 10, 12, 15 and 20ms). Each of the gaps is presented six times on all items of each track - a total of 60 gaps per track. Up to three gaps per noise segment are presented and some segments do not contain gaps1,8.

The practice track was applied before the test, thus ensuring that the subjects have clearly understood the procedures. Scientific studies have shown that the four tracks are equivalent 1,9. Therefore, in the present study, only two tracks were used. The test was initiated either by the right or the left ear but the first track was always the one primarily applied.

Participants were instructed to press a response button every time they heard the gaps embedded in noise. Absence of response was noted in the case when the gap occurred but the button was not fired. Correct answer was noted when the button was activated at the moment or seconds after the appearance of the gap. A false positive was considered when the button was activated without the presence of the gap - each participant could present up to two false positives per ear. From the third false positive, all subsequent ones were counted as errors and discounted from the total of correct responses on the calculation of the percentage of correct gap identification.

The performance on the GIN was derived from two measures8: the first measure - the approximate gap threshold - was defined as the shortest length of the gap identified on four out of six attempts; the second measure - the percentage of correct gap identification-was defined 
as a proportion of values, which was calculated from the sum of the gap intervals identified divided by the number of gaps presented on the track.

Statistical analyses were performed using descriptive statistics and non-parametric tests. The descriptive statistics aimed to represent the sample and the variables age, gender and ear. The non-parametric methods were used because the measures of the GIN test did not present a normal distribution (Gaussian distribution). Therefore, the Mann-Whitney test was used to analyze the difference of the GIN test measures between two groups. The Wilcoxon's test was used to compare the absolute difference between the first and second test tracks, and between the right and left ears.

The significance level determined was 0.05 with the calculation of $95 \%$ confidence intervals.

\section{Results}

The mean values of the gap detection threshold as well as of the percentage of correct gap identification will be presented.

Table 1 displays the results of the GIN test and p-values calculated through the Mann-Whitney test regarding the analysis of gender and ear. No statistically significant differences between ears were observed such for the comparison of gap thresholds as for the percentage of correct gap identification. Still in this table, results regarding the age groups studied (11 and 12 years) are shown. No statistically significant difference between the age ranges is observed. This way, responses of both age groups can be consider as responses of one single group.
Table 2 presents the results of the descriptive measures of the GIN test for the total sample, considering the ear and the track tested. P-values calculated through the Wilcoxon's test can also be observed on Table 2. The GIN test results were analyzed according to age, gender and ear. Results from the 92 individuals referring to thresholds means and percentages of correct gap identification were analyzed for each track. In fact, this was the only comparison in the present study in which statistically significant difference was observed, more specifically the percentage of correct gap identification. Significantly higher percentages were observed for the first track in comparison to the second one. When analyzing the results between the ears, the absolute variation showed no statistically significant difference for any of the measures studied.

Since there were no statistically significant differences between the variables age, gender and ear, a general data analysis was performed. Data pertaining to the variable subgroups were then summed and the results of 184 ears were considered for further analyses.

Table 3 shows descriptive statistics regarding the values of mean, standard deviation (SD), median, minimum and maximum gap threshold and percentage of correct responses observed in the total sample of subjects.

The threshold of $5 \mathrm{~ms}$ was the most frequently observed one (53.27\%) when analyzing the total sample. The sample of this study was distributed as follows in relation to gap thresholds: $2.17 \%$ presented threshold at 3ms; $22.83 \%$ at $4 \mathrm{~ms} ; 16.3 \%$ at $6 \mathrm{~ms}$; and $5.43 \%$ at $8 \mathrm{~ms}$. Thus, for the total sample, $78.27 \%$ of participants obtained the gap thresholds that were up to $5 \mathrm{~ms}$. 
TABLE 1. Descriptive measures of gap thresholds (ms) and percent of correct gap identification (\%), by gender and ear, and pvalues calculated for comparison

\begin{tabular}{|c|c|c|c|c|c|c|c|c|}
\hline & Variable & & Mean & $\mathrm{SD} / \mathrm{SE}$ & Median & Minimum & Maximum & p-value \\
\hline \multirow{8}{*}{ Gender } & \multirow{2}{*}{ Threshold RE } & Male & 4,9 & 1,1 & 5,0 & 3 & 8 & \multirow{2}{*}{0,49} \\
\hline & & Female & 5,1 & 1,0 & 5,0 & 4 & 8 & \\
\hline & \multirow{2}{*}{ Threshold LE } & Male & 5,0 & 1,0 & 5,0 & 3 & 8 & \multirow{2}{*}{0,058} \\
\hline & & Female & 5,3 & 0,9 & 5,0 & 4 & 8 & \\
\hline & \multirow{2}{*}{$\% \mathrm{RE}$} & Male & 72,4 & 7,2 & 73,3 & 55,0 & 88,3 & \multirow{2}{*}{0,41} \\
\hline & & Female & 71,6 & 5,4 & 71,7 & 58,3 & 83,3 & \\
\hline & \multirow{2}{*}{$\% \mathrm{LE}$} & Male & 72,4 & 7,3 & 73,3 & 56,7 & 86,7 & \multirow{2}{*}{0,17} \\
\hline & & Female & 70,4 & 6,6 & 71,7 & 58,3 & 81,7 & \\
\hline \multirow{8}{*}{ Age } & \multirow{2}{*}{ Threshold RE } & $11 \mathrm{y}$ & 5,2 & 1,1 & 5,0 & 4 & 8 & \multirow{2}{*}{0,099} \\
\hline & & $12 \mathrm{y}$ & 4,8 & 0,9 & 5,0 & 3 & 8 & \\
\hline & \multirow{2}{*}{ Threshold LE } & $11 \mathrm{y}$ & 5,2 & 0,9 & 5,0 & 4 & 8 & \multirow{2}{*}{0,30} \\
\hline & & $12 y$ & 5,0 & 1,0 & 5,0 & 3 & 8 & \\
\hline & \multirow{2}{*}{$\% \mathrm{RE}$} & $11 \mathrm{y}$ & 71,0 & 6,8 & 71,7 & 55,0 & 85,0 & \multirow{2}{*}{0,23} \\
\hline & & $12 y$ & 73,0 & 5,7 & 71,7 & 63,3 & 88,3 & \\
\hline & \multirow{2}{*}{$\% \mathrm{LE}$} & $11 y$ & 71,0 & 6,9 & 71,7 & 56,7 & 81,7 & \multirow{2}{*}{0,62} \\
\hline & & $12 y$ & 71,9 & 7,1 & 73,3 & 58,3 & 86,7 & \\
\hline
\end{tabular}

Legend: SD - standard deviation; SE - standard error for p delta; (pvalue) calculated through the Mann-Whitney test

TABLE 2. descriptive measures of gap thresholds (ms) and percentages of correct gap identification, by ear and track, and p-values calculated for comparison

\begin{tabular}{|c|c|c|c|c|c|c|c|c|}
\hline & Variable & Mean & $\mathrm{SD} / \mathrm{SE}$ & Median & Minimum & Maximum & CI of $95 \%$ & p-value \\
\hline \multirow{4}{*}{ Ear } & Threshold RE & 5,00 & 1,04 & 5,0 & 3 & 8 & 4,79 a 5,21 & \multirow{2}{*}{0,35} \\
\hline & Threshold LE & 5,11 & 0,93 & 5,0 & 3 & 8 & 4,92 а 5,30 & \\
\hline & $\% \mathrm{RE}$ & 71,99 & 6,34 & 71,7 & 55,0 & 88,3 & 70,68 a 73,30 & \multirow{2}{*}{0,34} \\
\hline & \% LE & 71,41 & 6,98 & 71,7 & 56,7 & 86,7 & 69,96 a 72,85 & \\
\hline \multirow{4}{*}{ Track } & Threshold $1^{\circ}$ test & 4,97 & 0,94 & 5,0 & 3 & 8 & 4,77 a 5,16 & \multirow{2}{*}{0,089} \\
\hline & Threshold $2^{\circ}$ test & 5,14 & 1,02 & 5,0 & 3 & 8 & 4,93 а 5,35 & \\
\hline & $\% 1^{\circ}$ test & 72,61 & 6,50 & 73,3 & 55,0 & 86,7 & 71,28 a 73,94 & \multirow{2}{*}{$0,002 *$} \\
\hline & $\% 2^{\circ}$ test & 70,80 & 6,73 & 71,7 & 55,0 & 88,3 & 69,42 a 72,17 & \\
\hline
\end{tabular}

Legend: SD - standard deviation; SE - standard error for p delta; (pvalue) calculated through the Wilcoxon test

TABLE 3. descriptive measures of gap thresholds (ms) and percentages of correct gap identification, in the total sample of subjects

\begin{tabular}{cccccccc}
\hline Variable & $\mathrm{n}$ & Mean & SD/SE & Median & Minimum & Maximum & CI of 95\% \\
\hline General Threshold & 184 & 5,05 & 0,98 & 5,0 & 3 & 8 & 4,91 a 5,20 \\
\hline General \% & 184 & 71,70 & 6,66 & 71,67 & 55 & 88,3 & 70,74 a 72,67 \\
\hline
\end{tabular}

Legend: $\mathrm{n}$ - number of individuals; SD - standard deviation; SE - standard error

\section{Discussion}

When considering that temporal processing is closely related to the perception of suprasegmental aspects of speech - once it involves the ability to perceive and store the non-verbal acoustic stimuli the deficit on the perception of temporal stimuli can lead to poor performance on reading and learning in general10-11. Thus, resources that assess temporal resolution are essential in the battery of tests that assesses auditory processing 12.
Research using the GIN test to assess the threshold of gap detection in individuals with hearing within normal limits reported values of gap thresholds ranging from 3.98 to $6.07 \mathrm{~ms}$.

Musiek et al. 1, in a study assessing individuals from 13 to 46 years, reported the gap threshold of 4.8 $\mathrm{ms}$ for the left ear and $4.9 \mathrm{~ms}$ for the right one, and the percentage of correct gap detection of $70 \%$ bilaterally. 
Chermak and Lee13 compared the performance of 10 children with normal hearing, aged from 7 to 11 years, on four tests of temporal resolution: Random Gap Detection Test (RGDT), Auditory Fusion TestRevised (AFTR), Binaural Fusion Test (BFT) and Gap In Noise (GIN). In the GIN test, the mean gap threshold reported was $4.6 \mathrm{~ms}$ for the right ear and $4.9 \mathrm{~ms}$ for the left ear.

Samelli and Schochat14 observed similar gap thresholds for both ears when studying 100 young adults from 18 to 31 years. Even without statistical significance, the authors observed the presence of best thresholds for men in both ears9. The overall mean gap threshold was $4.19 \mathrm{~ms}$ and the mean percentage of correct gap identification was $78.89 \%$.

Zaidan et al. 15 have also assessed the performance of young adults by comparing the responses of two temporal resolution tests: RGDT and GIN. Regarding the GIN test, the authors reported statistically significant different performance between genders - better responses were observed for the group of men when compared to the one of women. However, no statistically significant differences were observed in the comparison between ears - gap threshold of $5.38 \mathrm{~ms}$ for the right ear and $4.88 \mathrm{~ms}$ for the left ear.

Balen et al. 16 studied the temporal resolution of 10 children with normal development aged from 6 to 14 years. The authors analyzed the performance of children from the sample on the RGDT and the GIN tests. The mean gap threshold observed for the GIN test was $5.7 \mathrm{~ms}$ for the right ear and $5.4 \mathrm{~ms}$ for the left ear, with no statistically significant difference regarding ear and gender.

When comparing the results of the present study to those observed in the literature, it is noted that, on the present study, there was a perceptual symmetry between the right and left ears on the GIN test, which is consistent with the literature1,14-16. This shows that the monaural tests are useful in detecting alterations on the auditory pathway, but not in localizing such alterations - the involvement of ipsilateral and contralateral pathways result in similar performance of right and left ears17.

Furthermore, we observed that the boys performed better regarding the mean gap threshold and the mean percentage of correct gap detection in both ears. However, such difference was not considered statistically significant. These results are consistent with a study9 in which slightly better performances were observed for males in both ears. However, our findings differ from another study15 whose authors reported having observed better performance of men with a statistically significant difference in relation to women.

Exposure to high levels of testosterone can potentially delay the development of the left hemisphere and stimulate the development of the right hemisphere18. Thus, the advantage of males over females in temporal processing tasks may be related to a hormonal influence on brain development, but further studies involving the ability of temporal resolution are needed in order to clarify this difference.

Regarding to age, the present study showed no statistically significant difference in performance between 11 and 12 years. Gap thresholds found in this study were similar to those observed in studies using the GIN test, both in children 13,16 and in adults $1,9,14,15$. Therefore, we agree with the author of the GIN8 test when reporting that there are few maturational influences on this test. This fact suggests that the temporal skills at age 11 are developed and are little influenced by learning.

When comparing the tracks regarding the percentage of correct responses, it was observed that statistically significant higher accuracy was presented on the first track in comparison to the second one - i.e. on average there was a decrease of $1.81 \%$ on the second track in relation to the first one.

Such data do not coincide with the literature findings which report no statistically significant difference among tracks of the GIN test. However, the majority of studies reported carried out hearing test in adults1,9,14,15, differing from the current study. Even without studies in the literature that report differences among tracks, we found that the estimated time for the application of two tracks of the test is about 15 minutes. In a study16 performed with children, the participants argued that the GIN was a boring test. For this reason, the careful selection of tests to compose the assessment of auditory processing should be taken into account. The battery of auditory processing tests should not be long19,20. It is then necessary to evaluate the amount of time necessary to the completion of the test in order to make it suitable for clinical use. Knowledge regarding such differences is important for the definition of assessment protocols.

The confidence interval obtained for each track can be used as a guide for future studies. It should be highlighted that the present study was carried out with a sample of children with ages of 11 and 12 years. This way, further studies should be performed with younger children in chase for a wider definition of normality criteria. 


\section{Conclusions}

Based on the results of the present study, we conclude that:

. the mean gap threshold was 5.05 ms, while the mean percentage of correct gap identification was $71.70 \%$ for the total sample;

. no statistically significant differences between age groups (11 and 12 years), ear (left and right) and gender (boy and girl) were observed regarding performance on the GIN test;

\section{References}

1. Musiek FE, Shinn JB, Jirsa R, Bamiou DE, Baran JA, Zaidan E. GIN (Gaps in Noise) test performance in subjects with confirmed central auditory nervous system involvement. Ear Hear. 2005;26(6):608-18

2. Buonomano DV, Karmarkar RU. How Do We Tell Time? Neuroscientist. 2002;8(1):42-51.

3. Plack C, Viemeister N. Suppression and the dynamic range of hearing. J Acoust Soc Am. 1993:976-82.

4. Purcell DW, John SM, Schneider BA, Picton TW. Human temporal auditory acuity as assessed by envelope following responses. J Acoust Soc Am. 2004;116:3581-93.

5. Metherate R, Kaur S, Kawai H, Lazar R, Liang K, Rose HJ. Spectral integration in auditory cortex: mechanisms and modulation. Hearing Research. 2005;206:146-58.

6. Nicholas JG, Geers AE. Effects of early auditory experience on the spoken language of deaf children at 3 years of age. Ear Hear. 2006;27:286-98.

7. Trehub SE, Henderson JL. Temporal resolution in infancy and subsequent language development. J Speech Hear Res. 1996;39:1315-20.

8. Musiek FE, Zaidan EP, Baran JA, Shinn JB, Jirsa RE. Assessing temporal processes in adults with LD: the GIN test. Proceedings of the 2004 Convention Of American Academy of Audiology, Salt Lake City; march-april 2004. p. 203.

9. Samelli AG. O Teste GIN (gap in noise): limiares de detecção de gap em adultos com audição normal [Tese de doutorado]. São Paulo: Faculdade de Medicina da Universidade de São Paulo; 2005.

10. Pereira LD. Processamento auditivo: aspectos atuais. In: Encontro Internacional de Audiologia. [cd-rom] São Paulo: Resumo de trabalhos apresentados; 2005.
. confidence intervals for the mean gap thresholds were defined as: values from 4.77 to $5.16 \mathrm{~ms}$ for the first track, and values from 4.93 to $5.35 \mathrm{~ms}$ for the second track.

. confidence intervals for the percentages of correct gap identification were defined as: values from 71.28 to $73.94 \%$ for the first track, and values from 69.42 to $72.17 \%$ for the second track;

. for $78.27 \%$ of the sample, the gap thresholds obtained were up to $5 \mathrm{~ms}$ - value recommended as a normal reference for the age group studied.

11. Muniz LF, Roazzi A, Schochat E, Teixeira CF, Lucena JA. Avaliação da habilidade de resolução temporal, com uso do tom puro, em crianças com e sem desvio fonológico. Rev CEFAC. 2007;9(4):550-62.

12. Emanuel DC. The auditory processing battery: survey of common practices. Journal of the American Academy of Audiology, Burlington. 2002;13(2):93-117.

13. Chermak GD, Lee J. Comparison of Children's Performance on Four Tests of Temporal Resolution. J Am Acad Audiol. 2005;16:554-63.

14. Samelli AG, Schochat E. The gaps-in-noise test: gap detection thresholds in normal-hearing young adults. Int $\mathrm{J}$ Audiol. 2008;47(5):238-45.

15. Zaidan E, Garcia AP, Tedesco MLF, Baran JA. Desempenho de adultos jovens normais em dois testes de resolução temporal. Pró-Fono Revista de Atualização Científica. 2008;20(1):19-24.

16. Balen SA, Liebel G, Boeno MRM, Mottecy CM. Resolução temporal de crianças escolares. Rev CEFAC. 2009;11(1):52-61.

17. Baran J, Musiek FE. Behavioral Assessment of the Central Auditory System. Em: Musiek FE, Rintelmann W (eds.) Contemporary Perspectives on Hearing Assessment. Boston: Allyn \& Bacon; 1999. cap.13.

18. Rosen GD, Sherman GF, Galaburda AM. Ontogenesis of cortical asymmetry: A [3H] thymidine study. Neuroscience. 1991;7:3198-206.

19. Musiek FE, Baran JA. Assessment of the human central auditory nervous system. In: Altschuler RA, et al. Central auditory system. New York: Raven Press Ltd. 1991.

20. Jerger J, Musiek FE. Report of the consensus conference in the diagnosis of auditory processing disorders in schoolaged children. J Am Acad Audiol. 2000;11(9):467-74. 